\title{
REGENERASI PEMEROLEHAN SENI LAIS DI PADEPOKAN LAIS PANCAWARNA KAMPUNG SAYANG DESA CIBUNAR KECAMATAN CIBATU KABUPATEN GARUT
}

\author{
Ayu Septiani ${ }^{1}$, Asri Soraya Afsari ${ }^{2}$ \\ Universitas Padjadjaran ${ }^{1,2}$ \\ ayu.septiani@unpad.ac.id ${ }^{1}$
}

\begin{abstract}
ABSTRAK
Tulisan ini bertujuan untuk mengetahui eksistensi dan pemerolehan Seni Lais di Padepokan Lais Pancawarna. Tulisan ini menggunakan metode etnografi yang merujuk kepada penelitian kualitatif. Adapun sumber data yang digunakan terbagi dua, yaitu sumber data primer dan sumber data sekunder. Sumber data primer yaitu data di lapangan melalui participant observation. Selanjutnya, untuk data sekunder digunakan sumber kepustakaan. Hasil penelitian ini bahwa Seni Lais merupakan seni tradisional Garut yang hampir punah di Garut. Untuk melestarikan Seni Lais ini menggunakan tiga model pewarisan yaitu pewarisan tegak yaitu diturunkan dari genetik, pewarisan miring yaitu dilakukan dengan orang lain melalui pendidikan formal maupun normal dan pewarisan mendatar yaitu dengan melatih anak atau teman sebaya dilingkungan masyarakat. Kesimpulan perlu adanya pelestarian budaya salah satunya dengan mewarisi kebudayaan kepada generasi muda sebagai penerus bangsa.
\end{abstract}

Katakunci: Model Transfer, Regenerasi, Seni Lais.

\begin{abstract}
This paper aims to determine the existence and acquisition of Lais Art in Padepokan Lais Pancawarna. This paper uses ethnographic methods that refer to qualitative research. The data sources used are divided into two, namely primary data sources and secondary data sources. Primary data sources are data in the field through participant observation. Furthermore, for secondary data used library sources. The results of this study that Lais Art is a traditional art of Garut which is almost extinct in Garut. To preserve Lais Art, it uses three models of inheritance, namely upright inheritance, inherited from genetics, inherited inheritance, which is carried out with others through formal or normal education and horizontal inheritance, namely by training children or peers in the community. The conclusion is the need for cultural preservation, one of which is by inheriting culture to the younger generation as the nation's successors.
\end{abstract}

Keywords: Model of Inheritance, Regeneration, Seni Lais 


\section{PENDAHULUAN}

Indonesia dikenal sebagai negara yang kaya dengan beragam budaya. Seperti yang diungkapkan oleh Koentjaraningrat (2004), bahwa kebudayaan Indonesia mencakup bahasa, sistem pengetahuan, sistem kemasyarakatan atau organisasi sosial, sistem peralatan hidup dan teknologi, sistem mata pencaharian hidup, sistem religi, dan kesenian. Berdasarkan pendapat dari Koentjaraningrat tersebut, kesenian merupakan bagian dari kebudayaan yang wujudnya dapat berupa ide, aktivitas, dan artefak (Koentjaraningrat, 2003).

Secara umum, seni dibagi menjadi dua yaitu seni pakai dan seni murni. Seni pakai merupakan hasil karya cipta yang sengaja dibuat dan bermanfaat bagi kehidupan sehari-hari masyarakat, seperti seni ukir, pahat, dan kriya. Sementara itu, seni murni merupakan seni yang dapat dinikmati secara langsung seperti seni patung, lukisan, dan seni pertunjukkan.

Sebagaimana dikutip dari Online Etymology Dictionary melalui http://www.etymonline.com dalam Ekonomi Kreatif: Rencana Pengembangan Seni Pertunjukan Nasional 2015-2019 (Minarti, dkk., 2015), jika dilihat dari sudut pandang perkembangan etimologisnya, istilah seni pertunjukan merupakan serapan dari istilah bahasa Inggris performing arts yang berkembang di Eropa pada 1300-an. Kata perform merupakan kata serapan dari bahasa Prancis, parfornir ("par" dalam bahasa Inggris berarti completely + "fornir" jika diterjemahkan ke dalam bahasa
Inggris berarti to provide) yang berarti melakukan, menyelenggarakan, menyelesaikan, ataupun mencapai.

Seiring dengan perkembangan kegiatan teatrikal atau musikal pada 1600-an, kata perform kemudian dipahami melalui sudut pandang tata bahasa Inggris yang artinya meliputi: 1) to make (membuat), construct (membangun); produce (memproduksi), bring about, 2) (menimbulkan), atau come true (mencapai), 3) present (kata kerja transitif - memerlukan objek dalam kalimatnya) yaitu mempersembahkan, menyajikan (kepada penonton).

Dengan demikian seni pertunjukkan dapat diartikan sebagai aktivitas yang memiliki nilai seni yang didalamnya terdapat para penampil (performers) dimana mereka melakukan interpretasi terhadap suatu materi kepada penonton (audiences); baik melalui tutur kata, musik, gerakan, tarian, dan akrobat. Unsur terpenting dari seni pertunjukan adalah terjadinya interaksi secara langsung (live) antara penampil dan penonton, walaupun elemen pendukung seperti film atau materi rekaman termasuk di dalamnya.

Berdasarkan definisi tersebut, maka dapatlah dipahami bahwa seni pertunjukan mencakup teater, tari, , pencak silat, musik, dan akrobat. Seni pertunjukkan tersebut tentu saja tidak berdiri sendiri-sendiri, artinya mereka dapat saling berkolaborasi untuk menyajikan pertunjukan seni tertentu. Seni akrobat yang terdapat di wilayah Jawa Barat di antaranya Seni Genjring Akrobat di Indramayu dan Cirebon, serta Seni Lais di Wilayah Garut. 
Berkaitan dengan penelitian ini, penulis membahas regenerasi pemerolehan Seni Lais yang masih eksis dan berkembang yang dikelola oleh organisasi Padepokan Lais Pancawarna di Garut, tepatnya di Kampung Sayang, Desa Cibunar, Kecamatan Cibatu, Kabupaten Garut.

Pemilihan tema Seni Lais dilatarbelakangi oleh sudah mulai punahnya Seni Lais bahkan di wilayah tempat lahirnya seni ini yaitu di Kampung Nangka Pait, Kecamatan Sukawening, Kabupaten Garut, Seni Lais sudah punah dan tidak lagi dipertunjukkan. Selain itu, sejauh penulis ketahui, pembahasan mengenai Seni Lais masih sangat sedikit.

Karya tentang Seni Lais yang penulis ketahui di antaranya artikel berjudul "Upaya Pelestarian Kesenian Khas Desa Mekarsari dan Desa Simpang, Kecamatan Cikajang, Kabupaten Garut" yang dimuat dalam Jurnal Dharmakarya: Jurnal Aplikasi Ipteks untuk Masyarakat Vol. 4, No. 1, Mei 2015, karya S. Ypsi Soemantri, Dian Indira, dan L.M. Indrayani.

Karya tersebut merupakan karya pengabdian pada masyarakat dalam rangka upaya pelestarian beberapa kesenian khas di Desa Mekarsari dan Desa Simpang, Kecamatan Cikajang, Kabupaten Garut. Seni Lais merupakan satu di antara seni yang dibahas. Karya ini menjadi referensi bagi penulis karena memberikan informasi pendahulu bagi penulis bahwa ada sebuah kesenian yang bernama Seni Lais di Kabupaten Garut. Selanjutnya, karya tentang regenerasi pemerolehan seni dalam hal ini tulisan berjudul "Regenerasi Pemerolehan Seni Kriya (Kerajinan Bordir) di Kawalu Tasikmalaya" yang disampaikan dalam Seminar Nasional Bahasa, Sastra, dan Seni di Fakultas Ilmu Budaya, Universitas Mulawarman, Samarina dan dimuat dalam Prosiding Seminar Nasional Bahasa, Sastra, dan Seni. 24-25 Oktober 2017. Samarinda: Fakultas Ilmu BudayaUniversitas Mulawarman.

Karya ini menjadi referensi bagi penulis karena memaparkan konsep regenerasi dan pemerolehan seni sehingga memberikan gambaran umum tentang bentuk-bentuk pemerolehan seni.

Seni Lais merupakan seni pertunjukkan yang termasuk dalam seni akrobat. Dikatakan seni akrobat karena para pemain Seni Lais memiliki kemahiran tertentu dalam melakukan berbagai ketangkasan seperti berjalan di atas tali, menggantungkan tubuh pada seutas tali, dan melilit tubuh dengan tali pada ketinggian 15 meter di atas permukaan tanah.

Berdasarkan hasil penelusuran penulis, Seni Lais tersebar di beberapa wilayah di Jawa Barat yaitu di Cianjur, Tasikmalaya, dan Garut. Namun demikian, dalam penelitian ini penulis membahas Seni Lais yang masih eksis dan berkembang hingga kini di Padepokan Lais Pancawarna yang terletak di Kampung Sayang, Desa Cibunar, Kecamatan Cibatu, Kabupaten Garut dan dipimpin oleh Ade Dadang. 
Sebagai bagian dari kebudayaan, tentu saja Seni Lais dipelajari secara turun temurun dari generasi ke generasi. Fokus pembahasan dalam tulisan ini adalah regenerasi pemerolehan Seni Lais di Kampung Sayang, Desa Cibunar, Kecamatan Cibatu, Kabupaten Garut. Oleh karena itu rumusan masalah yang disusun oleh penulis yakni bagaimana model pewarisan Seni Lais atau regenerasi Seni Lais di Kampung Sayang, Desa Cibunar, Kecamatan Cibatu, Kabupaten Garut sebagai bentuk upaya pelestarian budaya?

Adapun tujuan dari penulisan ini adalah untuk mengkaji terwujudnya model pewarisan Seni Lais di Kampung Sayang, Desa Cibunar, Kecamatan Cibatu, Kabupaten Garut sebagai wujud dari pengupayaan pelestarian Seni Lais di di Kampung Sayang, Desa Cibunar, Kecamatan Cibatu, Kabupaten Garut. Sementara itu, dari penelitian ini diharapkan dapat diketahui model pewarisan Seni Lais sehingga diperoleh pengetahuan tentang pembelajaran seni pertunjukkan.

\section{METODE PENELITIAN}

Tulisan ini menggunakan metode etnografi yang merujuk kepada penelitian kualitatif. Metode etnografi dalam penelitian ini merujuk pada metode etnografi yang diungkapkan oleh Spradley (1997) yang disebut analisis maju bertahap. Analisis data dilakukan sejak tahap pertama yaitu tahap pengumpulan data dan dilakukan secara bertahap hingga akhir penelitian. Peneliti menentukan akhir penelitian karena penelitian etnografi dapat mengungkapkan hasil penelitian kebudayaan yang sempurna dan komprehensif.

Adapun sumber data yang digunakan terbagi dua, yaitu sumber data primer dan sumber data sekunder. Untuk menjalin hubungan yang baik dengan informan, maka penulis melakukan participant observation sebagai sumber data primer. Pengamatan dilakukan ke lapangan atau ke lokasi penelitian untuk mengamati Seni Lais yang ada di lokasi penelitian. Pengamatan dilakukan terhadap aspek-aspek bentuk fisik Seni Lais.

Selanjutnya, untuk data sekunder digunakan sumber kepustakaan. Studi kepustakaan dilakukan di berbagai perpustakaan baik di lokasi penelitian maupun di kota-kota yang memiliki lembaga penyimpanan sumber tertulis. Di Jatinangor, studi kepustakaan dipusatkan di Perpustakaan Fakultas Ilmu Budaya UNPAD. Sementara itu, di Bandung, studi kepustakaan dipusatkan di Perpustakaan Daerah Propinsi Jawa Barat.

\section{HASIL DAN PEMBAHASAN \\ Deskripsi Seni Lais}

Seni Lais adalah satu di antara kesenian khas Garut selain kesenian Domba Garut. Berdasarkan tradisi lisan yang berkembang di masyarakat Kampung Sayang, Desa Cibunar, Kecamatan Cibatu, Kabupaten Garut. Pada masa Kolonial Belanda terdapat seorang pemanjat pohon kelapa bernama Laisan yang berasal dari 
Kampung Nangka Pait, Kecamatan Sukawening, Kabupaten Garut. Nama Laisan kemudian diabadikan menjadi nama Seni Lais. Selain itu, daerah Nangka Pait menjadi tempat Seni Lais berasal.

Laisan sangat pandai memanjat pohon. Oleh karena keahliannya tersebut, masyarakat selalu menonton Laisan ketika memetik buah kelapa. Biasanya, mereka menonton Laisan sambil bersorak dan menabuh benda yang ada di sekitarnya untuk menyemangati Laisan. Lambat laun hal tersebut menjadi sebuah kebiasaan sehingga para tokoh kesenian di daerah tersebut meminta agar keterampilan ini dimodifikasi untuk dipentaskan di depan khalayak ramai.

Dalam perkembangan selanjutnya, Seni Lais menjadi satu di antara kesenian yang ditampilkan dalam acara-acara tertentu, seperti Hari Ulang Tahun Kota Garut, acara pernikahan, acara syukuran khitanan, dan festival seni lainnya.

Seni Lais dimainkan pada seutas tali sepanjang 9 meter yang dipasang pada dua batang bambu setinggi 12 meter. Tali yang digunakan adalah tali tambang jenis manila atau tali tambang dadung. Tali tambang tersebut terbuat dari bahan sabuk pohon kelapa dengan bentuk materi yang kasar sehingga dapat menopang benda yang bebannya relatif berat, termasuk tubuh manusia. Adapun bambu yang digunakan adalah jenis bambu surat (Wawancara dengan Ade Dadang, Pimpinan Padepokan Lais Pancawarna pada 25 Februari 2018).
Pertunjukan Seni Lais diiringi oleh nayaga. Kelompok Seni Lais pimpinan Ade Dadang memiliki 15 orang yang berperan sebagai pengiring musik (nayaga) dalam setiap pertunjukan Seni Lais. Mereka terdiri dari pemain terompet, kendang, dogdog, dan gesrek.

Ada juga yang berperan sebagai pemain pencak silat sebagai bentuk kolaborasi seni. Selanjutnya, ada yang berperan sebagai pemain lawak karena ketika pelais (pemain Lais) berada di atas, pemain lawak yang berada di bawah berbincang-bincang dengan pelais yang isinya bobodoran (percakapan jenaka) (Wawancara dengan Ade Dadang, Pimpinan Padepokan Lais Pancawarna pada 25 Februari 2018).

Berdasarkan hasil wawancara penulis dengan Ade Dadang pada 25 Februari 2018, Pimpinan Padepokan Lais Pancawarna, pertunjukan Lais mula-mula dilakukan dengan terlebih dahulu memancangkan dua batang bambu di atas tanah. Kemudian, tali tambang direntangkan dan diikatkan di kedua ujung bambu tersebut dengan jarak sekitar 9 meter.

Selanjutnya, sebagai penanda bahwa pertunjukkan telah dimulai, dibunyikannlah tetabuhan. Dengan cekatan, pemain Lais memanjat tiang bambu tersebut seperti seekor kera dengan menggunakan kedua tangan dan kakinya.

Setelah sampai di atas, Pemain Lais duduk di ujung bambu dengan santai dan berleha-leha. 


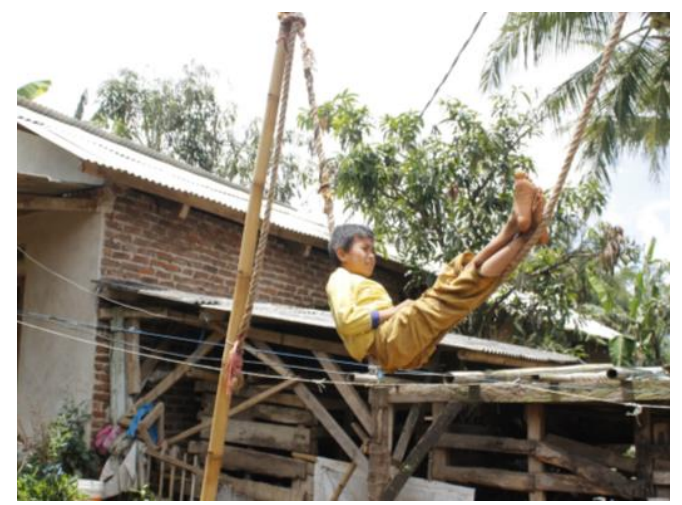

Gambar 1. Gerakan santai dan berlehaleha Pelais (Dokumentasi, 2018)

Gerakan selanjutnya adalah koprol yaitu gerakan berguling ke depan.

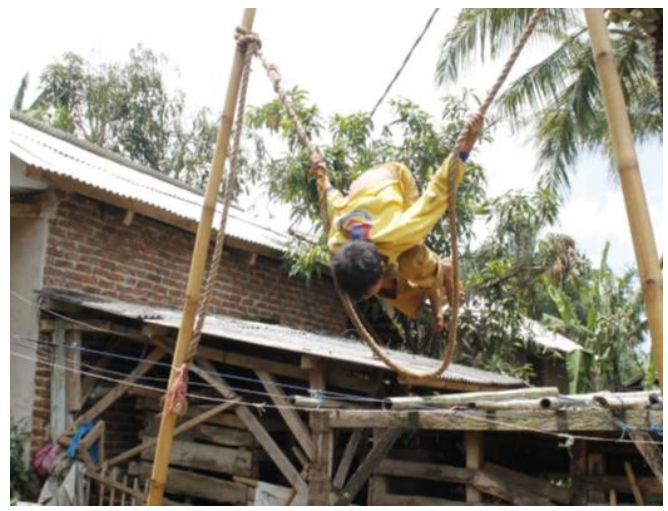

Gambar 2. Gerakan Koprol (Dokumentasi, 2018)

Selanjutnya, Pelais melakukan gerakan ngolecer (berputar).

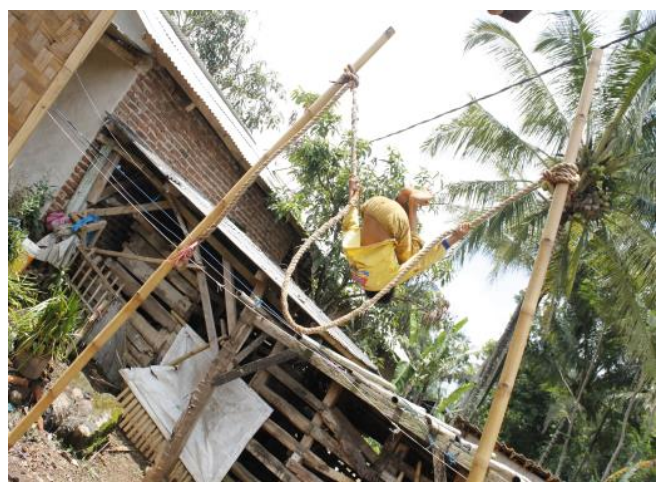

Gambar 3. Gerakan Ngolecer (berputar) (Dokumentasi 2018)
Berikutnya, gerakan Ngaitkeun Suku (mengaitkan kaki pada tali), posisi kepala berada di bawah.

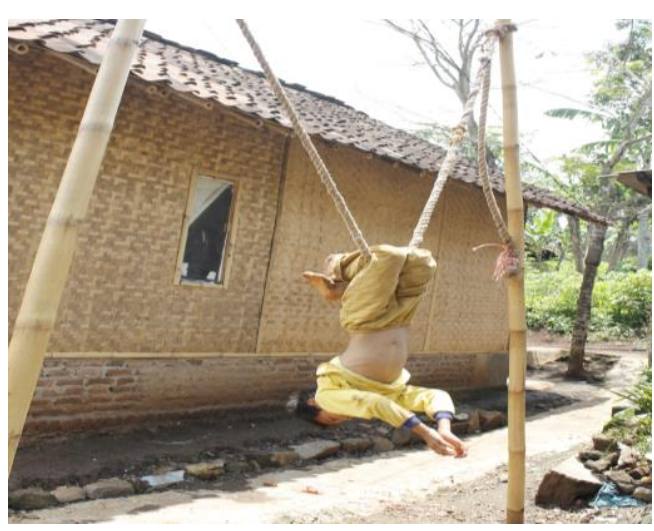

Gambar 4. Gerakan Ngaitkeun Suku (Dokumentasi, 2018)

Selanjutnya gerakan beulit kacang (gerakan membelit tubuh dengan tali tambang).

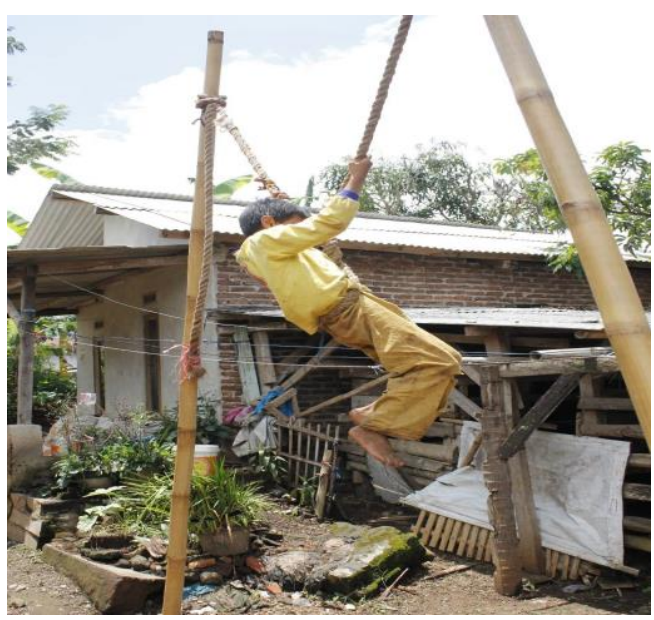

\section{Gambar 5. Gerakan Beulit Kacang} (Dokumentasi, 2018)

Dalam melakukan tiap-tiap gerakan, pelais tidak menggunakan pengaman. Hal inilah yang menarik perhatian penonton ketika menyaksikan pertunjukan Seni Lais. Selain itu, dari gerakan satu ke gerakan lainnya, biasanya diselingi percakapan bobodoran antara pelais 
dengan pemain lawak dan pawang (pemimpin pertunjukan agar penonton tidak jenuh ketika menyaksikan pertujukan Seni Lais.

\section{Model Pewarisan sebagai Bentuk Upaya Pewarisan Budaya}

Berdasarkan pengalaman dan pengamatan penulis dalam melakukan penelitian tentang Seni Lais, diketahui bahwa Seni Lais merupakan kesenian tradisional yang hampir punah dan hampir tidak dikenali oleh masyarakat Jawa Barat umumnya, dan masyarakat Garut khususnya. Beberapa kali penulis melakukan survey ke daerah dimana Seni Lais itu lahir yaitu di Kampung Nangka Pait, Kecamatan Sukawening, Kabupaten Garut dan daerah Salawu, Tasikmalaya. Namun, hanya sedikit dari masyarakat yang mengetahui tentang Seni Lais. Mereka pun mengatakan bahwa para pelais sudah meninggal dan tidak ada yang meneruskan.

Meskipun demikian, didorong oleh rasa penasaran penulis, maka penulis berusaha untuk menelusuri melalui situs internet dan kemudian menemukan berita tentang pertunjukkan Seni Lais yang dilakukan oleh Padepokan Lais Pancawarna yang terletak di Kampung Sayang, Desa Cibunar, Kecamatan Cibatu, Kabupaten Garut dan dipimpin oleh Ade Dadang dalam Laporan Wartawan Tribun Jabar, Hakim Baihaqi yang dimuat dalam tribunjabar.id pada Kamis, 22 Februari 2018. Berita tersebut mengabarkan bahwa selain kesenian Domba Garut, ternyata ada juga kesenian akrobat yang hampir punah di Garut, yaitu Seni Lais. Berbekal informasi dari tribunjabar.id tersebutlah penulis menelusuri padepokan Seni Lais yaitu Padepokan Lais Pancawarna di Kampung Sayang, Desa Cibunar, Kecamatan Cibatu, Kabupaten Garut.

Padepokan ini dipimpin oleh pelais bernama Ade Dadang, seorang pria kelahiran tahun 1966 (berusia 52 tahun). Ade Dadang menjadi pelais mula-mula dengan berguru pada seorang pelais senior bernama Mang Akim. Ade Dadang tidak berasal dari keluarga pelais. Orang tuanya, pamannya, atau leluhurnya tidak ada yang menjadi pelais. Namun demikian, Ade Dadang menurunkan keahliannya pada putra bungsunya yang berusia 9 tahun bernama Adit, seorang siswa sekolah dasar kelas 4 .

Selain menurunkan kepada putranya, Ade Dadang juga menurunkan keterampilannya kepada anak-anak yang ada di lingkungan rumahnya. Saat ini, jumlah muridnya sebanyak 15 orang. Murid-murid Ade Dadang berasal dari berbagai kalangan dan latar belakang keluarga. Kebanyakan dari murid-muridnya berusia sekitar 8-10 tahun atau setara kelas 4-6 SD.

Model pewarisan seni yang dilakukan oleh Ade Dadang dalam mewariskan keterampilannya di bidang Seni Lais sesuai dengan konsep yang dikemukakan oleh Cavalli-Sforza dan Feldman (dalam Adhiputra dalam Kusmaya, 2014). Menurut Cavalli-Sforza dan Feldman, terdapat tiga model pewarisan yaitu pewarisan tegak (vertical 
transmission), pewarisan miring (diagonal transmissions), dan pewarisan mendatar (horizontal transmissions). Model pewarisan tegak yaitu pewarisan berlangsung melalui mekanisme genetik yang diturunkan secara lintas generasi.

Model pewarisan miring yaitu pewarisan berlangsung melalui orang dewasa lain yang tidak memiliki ikatan genealogis seperti lembaga pendidikan formal, informal, dan non formal. Model pewarisan mendatar yaitu pewarisan berlangsung melalui teman-teman sebaya dalam lingkungan dimana seseorang berkembang sejak lahir sampai dewasa.

Ketiga model pewarisan Seni Lais digunakan di Padepokan Lais Pancawarna. Pewarisan tegak (vertical transmission) dilakukan oleh Ade Dadang kepada putra bungsunya. Pewarisan miring (diagonal transmissions) dilakukan oleh Ade Dadang kepada murid-muridnya yang ada di lingkungan sekitar tempat tinggalnya. Pewarisan miring dilakukan melalui pendidikan nonformal karena dilaksanakan di luar pendidikan formal namun memiliki jenjang atau terstruktur. Sementara itu, pewarisan mendatar (horizontal transmissions) dilakukan oleh putra dari Ade Dadang kepada teman-teman sebayanya di sela-sela latihan.

Dalam proses pewarisan tentu saja terdapat proses belajar. Seperti yang disampaikan oleh Cavalli-Spoza dan Fieldman dalam Berry dalam Kusmaya (2014) bahwa Cultural transmission can perpetuate its behavioral features among subsequent generations employing teaching and learning mechanisms. Berdasarkan kalimat tersebut penulis menyimpulkan bahwa dalam proses pewarisan atau pemerolehan seni terdapat kegiatan belajar mengajar. Generasi muda melakukan kegiatan belajar dan generasi tua melakukan kegiatan mengajar. Dengan kata lain generasi tua melakukan transfer ilmu kepada generasi muda terkait Seni Lais.

Sebagaimana penulis kutip dari pendapat Bruner dalam Hidayat (1990), proses belajar terjadi dalam 3 (tiga) episode yakni informasi, transformasi, dan evaluasi. Episode informasi adalah proses penjelasan, penguraian, atau pengarahan mengenai prinsip-prinsip struktur pengetahuan, keterampilan, sikap yang diharapkan setelah peserta didik melaksanakan proses belajar.

Adapun transformasi adalah proses peralihan atau pemindahan prinsip-prinsip struktur pengetahuan, keterampilan, dan sikap ke dalam diri peserta didik pada saat pelaksanaan proses belajar. Sementara itu, evaluasi adalah taraf penilaian untuk mengukur pencapaian peserta didik terhadap struktur pengetahuan, keterampilan dan sikap setelah peserta didik melaksanakan proses pembelajaran atau setelah guru mentranformasikan ilmu pengetahuan.

Berkaitan dengan pewarisan Seni Lais, episode informasi dimulai dengan kegiatan pengamatan yang dilakukan oleh murid. Pelatih memberikan penjelasan tentang Seni 
Lais serta menguraikan dan mengenalkan alat-alat yang dipakai dalam pertunjukkan Seni Lais, yaitu bambu dan tali tambang. Selanjutnya, pelatih memberi contoh tahapantahapan gerakan dalam pertunjukan Seni Lais, mulai dari naik bambu, gerakan di atas tali tambang, sampai turun kembali ke tanah.

Pada tahap inilah episode transformasi proses belajar dilakukan, yakni proses penyampaian prinsipprinsip struktur pengetahuan, keterampilan dan sikap ke dalam diri murid dimulai. Selanjutnya, proses transformasi ini dilakukan dalam dua tahap yaitu latihan fisik dan latihan gerakan Seni Lais. Latihan fisik meliputi lari, push up, back up, sit up, pull up, latihan keseimbangan tubuh, dan latihan pernafasan. Hal tersebut dilakukan dalam rangka latihan otot tangan dan kaki, serta untuk mengatur ritme pernafasan ketika melakukan Seni Lais. Latihan fisik ini berlangsung selama dua pekan dan dilaksanakan secara berkesinambungan. Latihan Seni Lais dilaksanakan pada sore hari setelah selesai sholat Ashar sampai menjelang waktu sholat Maghrib (Wawancara dengan Ade Dadang, Pimpinan Padepokan Lais Pancawarna pada 25 Februari 2018).

Setelah murid-murid dilatih secara intensif fisiknya, maka latihan selanjutnya adalah latihan memanjat bambu. Memanjat bambu merupakan tahapan kegiatan yang cukup sulit dilakukan karena kekuatan bertumpu pada tangan dan kaki. Setelah berhasil naik di atas tali tambang, selanjutnya, murid-murid berlatih gerakan, mulai dari gerakan bersantai, koprol, ngolecer, dan beulit kacang. Latihan dari gerakan satu ke gerakan berikutnya dilakukan secara bertahap. Artinya, murid harus lulus terlebih dahulu dalam melakukan gerakan bersantai di atas tali tambang, baru dapat melanjutkan latihan gerakan koprol. Jika gerakan koprol sudah dikuasai, maka latihan dilanjutkan ke gerakan salto, dan begitu seterusnya, sampai pada latihan gerakan turun dari bambu. Semua gerakan dalam Seni Lais ini menuntut keseimbangan tubuh, kekuatan tangan dan kaki, serta pengaturan pernafasan (Wawancara dengan Ade Dadang, Pimpinan Padepokan Lais Pancawarna pada 25 Februari 2018).

Episode proses belajar ini dilakukan secara simultan, artinya bersamaan dalam satu rangkaian latihan, termasuk episode evaluasi. Artinya, ketika murid keliru dalam melakukan suatu gerakan, pelatih langsung melakukan evaluasi bahwa gerakan tersebut salah dan kemudian pelatih mencontohkan kembali gerakan tersebut untuk selanjutnya ditiru oleh murid. Sehingga dapat dikatakan, proses belajar dari Seni Lais ini dilakukan secara bersamaan dalam satu rangkaian latihan.

Dengan demikian, pewarisan Seni Lais yang dilakukan oleh Ade Dadang dapat dikatakan sebagai suatu upaya pelestarian seni Sunda yang hampir punah bahkan di daerah asalnya sendiri. Tentunya, upaya pelestarian Seni Lais tersebut tidak dapat dilakukan tanpa dukungan dari 
masyarakat sekitar, pemerhati budaya, akademisi, dan pemerintah setempat. Sehingga peran serta semua elemen masyarakat harus ditingkatkan di tengah arus globalisasi yang kian gencar merasuki generasi muda Indonesia.

\section{SIMPULAN}

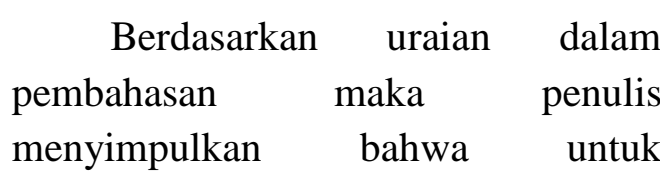
melakukan pelestarian budaya dapat dilakukan dengan berbagai cara. Satu di antara cara yang dapat dilakukan adalah dengan mewarisi kebudayaan kepada generasi muda sebagai penerus bangsa. Sebagaimana yang dilakukan oleh Ade Dadang melalui Padepokan Lais Pancawarna di Kampung Sayang, Desa Cibunar, Kecamatan Cibatu, Kabupaten Garut, dengan berbagi pengetahuan dan keterampilan dalam menampilkan pertunjukan Seni Lais yang hampir punah bahkan di daerah asalnya sendiri, Kampung Nangka Pait, Kecamatan Sukawening, Kabupaten Garut.

Kita patut berbangga hati bahwa masih ada anggota masyarakat yang peduli terhadap kelangsungan kebudayaan Indonesia sebagai jati diri dan identitas bangsa. Seyogyanya, semua elemen masyarakat turut serta berpartisipasi dalam upaya pelestarian budaya Indonesia agar generasi muda tidak hanya terampil dalam bidang teknologi tetapi juga kreatif dalam bidang kesenian tradisional.

\section{DAFTAR PUSTAKA}

Hidayat, K. (1990). Strategi Belajar Mengajar. Bandung: Tanpa Penerbit.

Koentjaraningrat. (2003). Pengantar Antropologi I. Jakarta: Rineka Cipta

_. (2004). Kebudayaan, Mentalitas, dan Pembangunan. Jakarta: Gramedia.

Kusmaya, A., Z. (2014). "Perkembangan dan Sistem Pewarisan Kesenian Angklung Badud di Cijulang Pangandaran". Universitas Negeri Yogyakarta, Yogyakarta. Tidak diterbitkan.

Minarti, H. (2015). Ekonomi Kreatif: Rencana Pengembangan Seni Pertunjukkan Nasional. Jakarta: Republik Solusi Melalui indonesiakreatif.bekraf.go.id diakses pada 3 Maret 2018 pukul 15.40 WIB. "Nayaga", melalui http://www. kamusbahasasunda.com/ diakses pada 10 Maret 2017

Septiani, A. (2017). "Regenerasi Pemer olehan Seni Kriya (Kerajinan Bordir) di Kawalu Tasikmalaya". Prosiding Seminar Nasional Bahasa, Sastra, dan Seni. 24-25 Oktober 2017. Samarinda: Fakultas Ilmu Budaya Universitas Mulawarman. ISSN 2598-487X. Soemantri, S. "Upaya Pelestarian Kesenian Khas Desa Mekarsari dan Desa Simpang, Kecamatan Cikajang, Kabupaten Garut". Dharmakarya. Jurnal Aplikasi Ipteks untuk Masyarakat. 4 (1), Mei 2015: 42-46.

Spradley, J., P. 1997. Metode Etnografi. Yogyakarta: Tiara Wacana. 


\section{Wawancara}

Ade Dadang, pimpinan Padepokan Padepokan Lais Pancawarna di

Kampung Sayang, Desa

Cibunar, Kecamatan Cibatu, Kabupaten Garut (52 tahun), 25 Februari 2018.

Adit, putra Bapak Ade Dadang (pewaris Seni Lais), (9 tahun), 25 Februari 2018 